\title{
The Disease Narrative in Albert Camus' The Plague
}

\author{
Ya Fen Huang ${ }^{1}$ \\ ${ }^{1}$ Assistant Professor, HungKuo Delin University of Technology, New Taipei City, Taiwan \\ Correspondence: Ya Fen Huang, Department of Applied English, HungKuo Delin University of Technology, \\ New Taipei City, Taiwan. E-mail: yfsonia@gmail.com
}

Received: September 20, 2020 Accepted: December 27, 2020 Online Published: January 4, 2021

doi:10.5539/ells.v11n1p1 URL: https://doi.org/10.5539/ells.v11n1p1

\begin{abstract}
In many literary works, a character's physical disease or illness also metaphorically references various universal characteristics of the human condition - death, religion, politics and relationships - as they are interworked amidst healthy and unhealthy bodies. In the case of Albert Camus' The Plague, the epidemic of bubonic plague in the Algerian port city of Oran is considered an allegory for the German occupation of France from 1940 to 1944. The highly infectious disease disrupts citizens' lives in real time, with consequences that further manifest throughout the world to varying degrees and in varying timeframes thereafter. This paper attempts to explore Camus's metaphoric connotations of "the plague" within these social, cultural and historical narratives. This interdisciplinary study will also bring together analyses of literary and non-literary texts about the disease narrative, while also addressing literary theories related to medical science in order to better understand the allegorical definitions of illness, death, disability and exile in The Plague.
\end{abstract}

Keywords: disease narrative, epidemics, discourse of illness, metaphors, The Plague, Albert Camus, Susan Sontag

\section{Introduction}

There is an idea quoted from the German philosopher Friedrich Wilhelm Nietzsche questioning whether we can still live without disease (Note 1). Similarly, the seventeenth-century clergyman and historian Thomas Fuller says that "health is not valued till sickness comes" (Note 2). With both, "getting a disease" is viewed metaphorically as part of life, with poor health implying "being alive;" that is to say, the dead cannot fall ill. Furthermore, sickness is ubiquitous and unavoidable, brought about by war, famine, genetic mutations, pandemics, injuries, natural disasters, and so on. "Illness," a quote from Nietzsche, is "a clumsy attempt to arrive at health: we must come to nature's aid with intellect" (Note 3). It means that people cannot realize the importance of being healthy until they are ill. The best one can do is to continuously focus on rationally treating and curing maladies and sympathizing emotionally with those who suffer. Despite advances in medical science and living standards worldwide, humanity still faces the catastrophic effects of various diseases, whether in a single individual or as a global pandemic. These lead to great hardships and suffering in the daily lives of individuals and also have a global influence diplomatically, economically, and even environmentally, making them a universal problem that all humankind must face.

From ancient times to the present, knowledge of diseases, including the relatively recent awareness and development of pathology (Note 4), has been theoretically constructed and clinically operationalized. Many medical innovations, such as penicillin, antibiotics and steroids, were found to cure diseases that were formerly fatal; vaccines likewise are certified as safe and effective in preventing such diseases. Despite this, people continue to suffer from life-threatening illnesses and injuries, which are like arrogant and relentless enemies. Medical treatment of diseased bodies provides great insight into a society and its history and culture throughout recorded history; these cultural norms and worldviews differ psychologically and ideologically, but will be synthesized into a new episteme - thus, the mode of knowledge that allows us to comprehend "diseases" is not only particular, but also universal in that the current generation can benefit from the wisdom of its predecessors. Likewise, the disease narrative is a literary form of pathology vis-à-vis the characters affected.

There is evidence to suggest that "you are what you eat," and sickness sometimes results from food that was tainted either intentionally or unintentionally by manufacturers, such as the accidents of "drainage oil" and contaminated food that shocked consumers a few years ago. The degradation of nutrition due to environmental 
contamination and soil overuse also is thought to contribute to disease, and to also offer clues about how to maintain health and prevent illness. If this can be taken to its logical extreme in this high-tech age, does this mean that someday there could be no more illness? Probably not; paradoxically, the medical community has made little progress in eliminating — or even fully understanding - viruses. The worldwide novel coronavirus pandemic of 2020 is just the most recent example and the economic and social disruption it caused seems to have been the greatest challenge for every nation around the world since World War II.

Out of such contexts emerges the "disease narrative" through which humans throughout history have constructed knowledge about various diseases and their symptoms in both literary and non-literary texts. These often function as historical records as characters suffering from diseases and illnesses are subjected to the current body of knowledge about pathology, pharmacy, pharmacology, and anatomy. In this way, the relevant vocabulary, psychoanalysis, and philosophical concepts or cultural discourses could be simultaneously presented and recorded in the literary narratives of disease, implying that literary works could help people understand the historical subtext about the relationship between illness and humanity throughout history.

In the first chapter of Illness as Narrative, "Illness Narrative and the Challenge to Criticism," Ann Jurecic provides wide-ranging examples of the narratives of illness in both literary and non-literary works; for example, "the pandemic is virtually absent from American and British literature of its era" (13); she also numerates the novels of Mary McCarthy, Thomas Wolfe and Will Cather (13), which she states place "the epidemic at the center of the plot" (13). In Albert Camus's novel The Plague, society is struck by disease as a result of war, and the people fighting in the battlefield-like space/environment of illness are compared to those who were part of the collective infection of the so-called Black Death in the fourteenth century. All of the characters become infected and feel powerless and destined for death, even while diligently combating the general pandemic and their individual ailments, realizing that all human beings eventually die. No matter when and how the pestilence occurs in the city of Oran in Camus's The Plague, the intersections between healthy and diseased bodies must be reconsidered and readjusted. This study aims to explore the discourse of illness and the interrelated effects among human diseases, misery and death. Furthermore, such an examination of the disease narrative enables readers to question whether traditional medical science and theories are still workable at an age of modernization.

\section{Theoretical Framework}

In the "Preface" of The Wounded Storyteller: Body, Illness, and Ethics, Arthur W. Frank explains his intention to transform traditional conceptions about illness from passivity into positivity, stating that the better approach is to think of "the ill person as a 'victim of' disease and then recipient of care- toward activity." Frank also points out that the literary works/litterateur narration of disease, like the English romantic poet John Keats and his work, are presented and pictured as an "aesthetic transformation of suffering, even death." The spectrum of experiences of an ill person, either physical and psychological, also has been adapted into literary narratives of individual sufferings in real life: "Their injuries become the source of the potency of their stories" (Preface, Frank). In his article "The Strange Case of Mr. Keats's Tuberculosis," Hillas Smith discusses John Keats's tragic death from tuberculosis at the age of 25, which became the representative image of some romantic poets of the 19th century. Advances in medical sciences, in the examples given by Hillas Smith, include "Koch's discovery of the pathogenic bacillus in 1882, the introduction of radiography in 1895, and the introduction of effective chemotherapy and useful vaccines." This progress notwithstanding, medical science failed to cure Keats's tuberculosis, making disease in literature as well as in this real-life example in part a metaphor for a much larger phenomenon.

The characters in Thomas Mann's The Magic Mountain are connected allegorically with the ill, as explained by Jayjit Sarkar in Illness as Method: Beckett, Kafka, Mann, Woolf and Eliot, reducing their symptoms to merely "disguised manifestations of the power of love" because all diseases are transformed through love (34). The American writer Susan Sontag similarly noted that "Milly Theale's doctor advises a love affair as cure for her TB" (21); in Henry James's novel The Wings of the Dove, Milly Theale is an American heiress stricken with tuberculosis. She influences those around her and is advised by her doctor to have a love affair in order to cure her illness-here, love becomes a systematic cure for physical and mental disorders. Either love or death is one part of life, because all humans ultimately go through the same stages of life, without exception. The complex connection between characters' mental disorders and bodily illnesses symbolically represents their similarly complex - indeed, often mystifying — relationships with others. Love, here, is measured by how much care the ill character receives from loved ones and others.

Moreover, studies have found that diseases such as cancer and dysautonomia (improper functioning of the 
autonomic nervous system) can be the result of repressed emotions of rage and similarly disordered mental states. In literature, a character's illnesses usually are ascribed to a failure — or at least an undesirable new element - in the character's life. Sickness manifests through pain, morbidity, suffering, or dying and death. Sontag has pointed out that certain diseases also could be caused from "too much passion, afflicting the reckless and sensual" (21); cancer, for example, is thought of as "a disease of insufficient passion, afflicting those who are sexually repressed, inhibited, unspontaneous, incapable of expressing anger" (21). Sontag has also claimed that "feelings about evil are projected onto a disease" (58). Similarly, anyone could be affected by pandemics or epidemics regardless of race, economic status, gender, or age. The characters in The Plague, regardless of their individual sociocultural status, become uniformly hopeless and resigned to their fate, because they could neither foresee nor control their lives in the face of an epidemic.

In addition to the cultural metaphors and symbols produced by maladies, physical illness or diseases also represent the collective sickness of discrete units as small as the family and as large as the nation or world. The late Oliver Sacks, a London-born author and professor of neurology who practiced medicine in New York, said that "my work and my life are all related to sick people," (Note 5) and that "animals get diseases, but only man falls radically into sickness" (Note 6) in The Man Who Mistook His Wife for a Hat. In this clinical memoir, Sacks turns medical records into stories, describing the process of curing various diseases from their onset through death of the patient. He noted that recovery does not necessarily mean a complete revitalization or restoration, because embedded memories from the process of being sick or wounded become an archive or knowledge base within one's body, engaging as a kind of intellectual discourse about disease and illness.

In the preface of The Man Who Mistook His Wife for a Hat, Sacks mentioned that the Greek physician Hippocrates, in History of Pathology, defines "pathology" as "a description of the natural history of disease." "Pathography" - not "pathology"-is the word used in ancient times, so the meaning of pathography is etymologically regarded as a written description of ancient history, not merely "his" story (Note 7). Indeed, knowledge of pathology on the one hand encompasses the collective narrative of all affected people's particular experiences; on the other hand, it also describes the process by which individuals alone face and struggle with their own quest for healing. Following the contributions of the Greek physician Hippocrates of Kos' traditional but universal pathology, there has been the gradual addition of invasive medication or medical surgery, alternative therapy, and psychological regimens and psychoanalysis, developed to treat or prevent disease. These medical treatments are not only used to develop more effective medicines, but also to inspire individuals to learn how to sustain and extend their lives. The question in this modern era still persists regarding whether the ill are afraid of facing the truth of their pending death.

This study aims to explore the discourse of illness and the interrelated effects among human diseases, misery and death in part by studying the French philosopher Michel Foucault's The Birth of the Clinic and The Order of Things. Especially in The Birth of the Clinic: An Archeology of Medical Perception, Foucault traces the development of the medical profession and the institutions of clinics and hospitals, which help define the concept of the "medical gaze." In his The Order of Things, he describes the sudden re-organization of medical knowledge at the end of the 18th century. The medical record of a disease is also the history of the symbioses between bodies and natural diseases, which result from the confrontation/coordination between the patients and their affected bodies. The concept of "episteme (Note 8)," in The Order of Things, is defined as the arrangements of discourses and modes of knowledge representing dissimilar historical and cultural conditions of possibilities within a particular epoch. Each episteme of disease narrative at a given time and place is distinct. Therefore, either medical description or pathology is used not only to describe or show the natural paths of disease development through research or reasoning, but also to ultimately attain an essential understanding of the illness. Disease narratives motivate people to pay more attention to the problematic struggles between life and weakened/diseased bodies as derived from the construction of medical archives and then form subjects of different worlds. In this way, disease narratives become epistemes of medical science.

From History of Madness to Discipline and Punish to The History of Sexuality: Introduction in the First Volume, Michel Foucault advocates that the concept of power and the elements of a discourse constitute "subjectivation" that is limited and formed by external conditions. A discourse could be regarded as power embodied inside of oneself, as seen in the way the mechanical management of a prison transfers the outside of a prisoner's bodily experiences into his inner self-management. In the same fashion, a patient is self-internalized and self-restrained through the discourse of the logistical management provided in a hospital (or even in a mental health facility, where a patient's deepest feelings are systematically extracted, causing a constant, oppressive feeling of restraint even after any physical shackles (or other repressive forms of external logistical management) have been removed. Therefore, the positive aspects of various historical contributions, such as medical science or pathology, 
should be more emphasized than subjective consciousness, idealism or teleology; the power of illness discourse ultimately could be constructed by disease narratives alone.

In Foucault and Literature: Toward a Genealogy of Writing, Simon During analyzes how the relationship between modern discourse and knowledge is studied in The Order of Things. During argues that Foucault's analysis of the production of power from discourse in different historical periods refers to a common phenomenon in classical society in which "power was fixed, visible, mappable" (117); and furthermore that "Foucault regards modern discourse as the dissolution of the a-temporal order of mathesis, as an attempt to appropriate the non-representable forces and conditions of historicity and life" (During 117). These may be the actual operations of discourse, the sayable/visible parts: to form a diseased body into a new research topic by means of how the medical treatments and the anatomy are described/said more in detail at a certain era. The discourse of illness, as the visible and sayable part of an otherwise ideological issue, also could be constructed by the disease narratives in literary works.

Under the guidance of Susan Sontag's "Illness as Metaphor and AIDS and Its Metaphors" in Illness as Metaphor and AIDS and Its Metaphors, this study also will explore the disease narrative and illness discourse described in Camus's The Plague, in which the intellectualized cultural codes and historical tracks of an epidemic are constructed. This paper also tries to analyze the metaphorical relationship between the disease narrative and the urban lives of those in Oran. Some disease metaphors signify something else in a society, such as cultural or social discrimination. Sontag indicates that most people think of those suffering with disease (Note 9) as "literally being "consumed' by a passion that was being driven inward" (20); the metaphors usually are created by the toll a disease takes on individuals and society, and how the conception of a disease in a particular society influences the methods of medical treatment and whether or not people accept every aspect, beneficial or harmful, of getting sick. In addition, epidemics are "a common figure for social disorder" (Sontag 58), so the meaning of pestilence is a figurative reference to "morally baneful or pernicious" (Sontag 58).

Just as sudden, natural calamities often catch people off guard, so, too, does a patient diagnosed with a fatal malady find the situation unthinkable and unacceptable, because to confront the truth of getting a disease likely also means confronting one's mortality. For the residents of Oran of The Plague, the outbreak is an "unwelcome visitant, bound to take its leave one day as unexpectedly as it had come" (98). Sontag has said that "as death is now an offensively meaningless event, so that disease widely considered a synonym for death is experienced as something to hide" (8). Our ultimate disposition - death — thus becomes our deepest dread. Still, to come to terms with death is imperative for those who are ill, like cancer patients who must accommodate hearing both the truth and lies from others: "all this lying to and by cancer patients is a measure of how much harder it has become in advanced industrial societies to come to teams with death (Sontag 8)". In Illness as Metaphor, Sontag also points out that a disease sometimes will be compared to a death sentence, because "it is felt to be obscene - in the original meaning of that word: ill-omened, abominable, repugnant to the senses" (9).

\section{The Plague}

Since earth's climate has undergone continuous change since the dawn of time, new diseases and disease patterns also have continuously emerged, each of which presents a specific epochal scenario. For example, tuberculosis was widespread in Britain during the Romantic period of the 19th century, and as treatments were developed for previously fatal illnesses, AIDS and cancer emerged as a new kind of the Black Death in the 20th century. This ongoing phenomenon constitutes the historical background of an era, just as the disaster of a plague is described in the Nobel Prize winner and French novelist Albert Camus's chronicle novel, The Plague (Black Death). In it, Camus delineates the plague, already well known over the course of human history. The absurdity of unexplained and sudden tsunami of death symbolizes all of the other similarly dark and incomprehensible aspects of life. People are caught off guard, with virtually no time to respond. The epidemic thus is used to articulate and test human attitudes toward disease and death, and to create out of violent destruction a collective vigilance in thereafter handling emergent events.

"In the past, such grandiloquent fantasies were regularly attached to the epidemic diseases, diseases that were a collective calamity" (Sontag 58); here, Sontag also points out one kind of narrative: "the diseases most often used as metaphors for evil were syphilis, tuberculosis, and cancer-all diseases imagined to be, preeminently, the diseases of individuals" (58-59). One of the reasons that disease can be used as a metaphor for disaster is that it not only is a profoundly negative experience that weakens and restricts the individual, but it also introduces divisiveness within the affected groups, especially those who educate the sick on how to face loneliness and death. An example is Dr. Rieux in The Plague, whose demeanor seems indifferent but who worries grievously in his heart: "Rieux had nothing to look forward to but a long sequence of such scenes, renewed again and again" 
(95). The people of Oran cannot help but consider the plague as "abstraction, [that] was monotonous; perhaps only one factor changed" (Camus 95). When disease comes to represent a fear of disaster on the part of the majority of people in Oran, they want to hide, suggesting that the epidemic as a metaphor for calamity and fear has never fully disappeared from human consciousness. The unique tasks associated with the treatment of disease, however, become uniquely terrifying, as noted by the narrator in The Plague:

What is more exceptional in our town is the difficulty one may experience there in dying. "Difficulty," perhaps, is not the right word; "discomfort" would come nearer. Being ill is never agreeable, but there are towns that stand by you, so to speak, when you are sick; in which you can, after a fashion, let yourself go.

Ian Watt, in The Rise of the Novel, deduces that the new literary form that emerged in the early eighteenth century involved "a break with the old-fashioned romances" in part through the use of realism (10). These novels further "attempt to portray all the varieties of human experience" (Watt 11). Therefore, assuming that readers are educated by stories or influenced by the ideology a novelist weaves between the lines of text, and that reality can be fully expressed through language, readers are mostly aware of the nuances between characters in novels as opposed to ordinary people in real life. The disease narrative describes the life of the illness, affirming the victims' hopelessness and helplessness in reality, just as social, cultural and political realities are simultaneously represented symbolically by novelists. For instance, in The Plague, unscrupulous politicians exploit people for personal gain during the height of the illness, but people's first reaction "was to abuse the authorities" (82). Although ordinary people bravely sought to defend themselves, they ultimately realize they are helpless and utterly at the mercy of others. At that point, the characters are forced to re-examine the meaning of their own individual existence and that of groups, and ask, which is more important? On the other hand, diseases are interpreted as being under the control of the prevailing social power discourse, which often labels those suffering from infectious diseases as evil and sinful, further isolating the sick from the critical framework of the dominant cultural force:

Nobody as yet had really acknowledged to himself what the disease connoted. Most people were chiefly aware of what ruffled the normal tenor of their lives or affected their interests. They were worried and irritated - but these are not feelings with which to confront plague. (Camus 82)

Camus's The Plague chronicles the ravages of disease in the Algerian port city of Oran. The residents are slow to recognize that they face mortal danger: "The word 'plague' had just been uttered for the first time... yet always plagues and wars take people equally by surprise" (The Plague 43). According to Patrick Henry's We Only Know Men: The Rescue of Jews in France During the Holocaust, Camus calls The Plague a "chronicle" rather than a novel because it literally tells the story of a pandemic disease taking place in the 1940s in France (setting in 1948, three years after the end of World War II), that contributes "physical, social, and metaphysical significance" (114). Henry calls it an "allegorical portrayal of the human condition, stressed in a series of explicit statements carefully placed throughout the text" (Henry, 114), and that "at each of these levels, Camus succeeds is depicting the themes of separation, exile, and isolation as central" (114). He also delineates the concept of "imprisonment" in this allegorical narrative (Henry, 114).

The residents of Oran find themselves living like captives (or exiles) as they suffer the most severe physical pain, eventually merely existing along with their useless memories of the remote past, memories that are steeped in regret and provoke regret over unfinished business. They hopelessly anticipate the end of the pestilence, hoping to make up for those regrets in the near future: "Nevertheless, many continued hoping that the epidemic would soon die out and they and their families be spared" (98). For some, the sense of isolation becomes a feeling of full-blown expatriation. The narrator of The Plague, sighing, says that "thus the first thing that plague brought to our town was exile" (76) and "it was undoubtedly the feeling of exile - that sensation of a void within which never left us, that irrational longing to hark back to the past or else to speed up the march of time, and those keen shafts of memory that stung like fire" (76). The epidemic becomes a prison that imposes limitations and restraints, causing all those affected to yearn to relive their memories or to move ahead to a time when the epidemic was behind them and new memories could be created.

The first narrative point of view comes from a hospital physician, Dr. Bernard Rieux, who is described by Tarrou as about thirty-five years old and of moderate height, with broad shoulders, dark skin, and close-cropped, black hair (37). As the narrator, Dr. Rieux cannot take into account of the various points of view; his prestigious position does not confer upon him the narrative gifts of omniscience and omnipotence. Still, he is the first to treat the first victim and to describe the outbreak as a plague. The danger he faces at the beginning of the novel seems unreal to him, and he feels uneasy about warning the authorities, because he does not yet recognize the gravity of 
the situation. Soon, however, it seems likely that the epidemic could kill half the town's population within a couple of months. Dr. Rieux then focuses on relieving human suffering solely in fulfillment of his obligation as a medical professional; he never obtains a belief in God or views medical treatments as having religious connotations like Father Paneloux, "a learned and militant Jesuit" priest in Oran (Plague, 24). Paneloux believes that even the most terrible suffering works ultimately for good (from Romans 8:28), because the whip of God always makes arrogant and blind people fall at His feet: "the scourge of God has humbled the proud of heart and laid low those who hardened themselves against Him" (99). In short, all humankind would do well to give in to their miseries. Even though Dr. Rieux as a narrator (Note 10) cannot explain all the phenomena occurring around him, he is a practical and direct man who declares the objective truth of what he observes and how events intimately affect the entire population, with "thousands of eyewitnesses who can appraise in their hearts the truth of what he writes (The Plague, 13)."

In times of calamity, survival, deformity, disability, illness and death provoke the majority of people to recognize the oppression and threats they have long faced and the atmosphere of exile they live in, leading most to turn to religion. In Camus's The Plague, people are infected with the physical and psychological disease because they have great fear and self-righteous ignorance of the things in the world. Camus here juxtaposes the absurdity of war with the helplessness of being enslaved by disease, one that torments individuals until it grows into a collective infection. The residents in Oran initially go on with their lives as usual, ignoring the gnawing reality that "no one will ever be free so long as there are pestilences" (Camus 44). By extension, the larger implication is that the plague is never far from the lives of any human being. Camus, who was part of the Nazi resistance in the Second World War, uses the disease and plague as metaphors for war, referring to the ultimate repetitiveness and preposterousness of history - to resist disasters or illnesses further underscores their absurdity.

Over time, the residents of Oran learn how to ignore the terrifying physical and psychological confines of their existence. From the religious point of view, the characters are able to overcome their fear of death (especially such a torturous death) when the epidemic is at its zenith: "At the height of the epidemic we saw only one case in which natural emotions overcame the fear of death in a particularly painful form" (Camus 75). All people must confront the end of their life on earth, but many continue to question why God allows innocent people to be tortured by suffering unto death. In this way, Father Paneloux's attitude can be seen as reflecting the message of the Book of Exodus in the Old Testament (Note 11). Disasters are a form of God's wrath toward those who are disobedient, but good people suffer, too: "The just man need have no fear, but the evildoer has good cause to tremble" (Camus 100). In the face of plague, people of all ages, men and women, rich and poor, are vulnerable. A virtuous life provides no protection. Rieux seems to realize the cruelty inherent in a natural order that seems to be controlled by constant threat of death:

In short, they were waiting for the turn of events. With regard to religion-as to many other problems - plague had induced in them a curious frame of mind, as remote from indifference as from fervor; the best name to give it, perhaps, might be "objectivity." (Camus 98)

\section{Conclusion}

Jean Tarrou, Rieux's best friend and one of the epidemic's last victims, keeps a diary with his observations of life in Oran, and the narrator Rieux incorporates Tarrou's notes into his narrative: "in those chaotic times he [Tarrou] set himself to recording the history of what the normal historian passes over" (Camus 30). Tarrou opposes the death penalty even though his father is a lawyer, an attitude representative of most of the residents in Oran at the time: "Tarrou had to admit he had no inside knowledge on the matter; his personal theory was that after the upheaval caused by the epidemic, there would be some delay in getting these services under way again (Camus 280)." Before the epidemic subsided, Tarrou organized a volunteer team against it, and he puts up a heroic struggle as he awaits his own death at the end of the chronicle. Malaise turns into stark terror and hopelessness, and becoming accustomed to the looming despair is worse than the experience of despair itself. Disease causes people to renew their attention to the struggle between healthy and abnormal, sickly bodies.

The plague here clearly refers to German Nazism, the German state between 1933 and 1945. Camus indicates allegorically that everyone recognizes the violent nature of Nazism as an epidemic, but not many people are willing to recognize it clearly, let alone to resist it effectively. Once the residents of Oran suffer from the epidemic, they no longer care about the things of the world. After a large proportion of Oran's population are killed by the pestilence, the survivors gradually give up their ability to choose and let any love they retain be replaced by blind attachments or material goods. As their fear of succumbing worsens, they squander their lives absurdly, buying all kinds of luxuries at exorbitant prices, dressing far beyond what is typical for attending plays and movies, and avoiding others outside these venues in order to prevent infection. The shadow of death looms 
over everyone: judge and porter, priest and apostate, adult and child. Since death is an equalizer, any superficial inequalities also become equalizers. Disease narratives and their cultural metaphors in contemporary novels like The Plague refer to the orderly management of disease or medical treatments derived from the construction of archives and the formation of subjects of different worlds into the veneer of society. Violence and misery caused by natural calamities and maladies push everyone into exile, as brilliantly illustrated by the spread of plague in Camus's chronicle novel.

\section{References}

Camus, A. (1975). The Plague (Trans. by Stuart Gilbert). New York: Vintage Books.

Charon, R. (2006). Narrative Medicine: Honoring the Stories of Illness. New York: Oxford University Press.

During, S. (1992). Foucault and Literature: Toward a Genealogy of Writing. London: Routledge.

Foucault, M. (1970). The Order of Things: An Archaeology of the Human Sciences. New York: Vintage Books.

Foucault, M. (1973). The Birth of the Clinic: An Archaeology of Medical Perception (Trans. by A. M. Sheridan Smith). New York: Vintage Books.

Foucault, M. (2008). The Birth of Biopolitics: Lectures at the College de France (Trans. by Graham Burchell). New York: Palgrave Macmillan.

Frank, A. W. (1995). The Wounded Storyteller: Body, Illness, and Ethics. Chicago: The University of Chicago Press. https://doi.org/10.7208/chicago/9780226260037.001.0001

Henry, P. (2007). We Only Know Men: The Rescue of Jews in France During the Holocaust. Washington D. C.: The Catholic University of America Press.

Jurecic, A. (2012). Illness as Narrative. Pittsburgh: University of Pittsburgh Press. https://doi.org/10.2307/j.ctt5hjr8p

Nayar, P. K. (n.d.). Diseases, Devastation and Poetry.

Sack, O. (1995). The Man Who Mistook His Wife for a Hat. London: Picador. https://doi.org/10.1192/bjp.166.1.130

Sarkar, J. (2019). Illness as Method: Beckett, Kafka, Mann, Woolf, and Eliot. Wilmington, Vernon Press.

Smith, H. (2004). The Strange Case of Mr. Keats's Tuberculosis. Clinical Infectious Diseases, 38(7), 991-993. https://doi.org/10.1086/381980

Sontag, S. (1989). Illness as Metaphor and AIDS and Its Metaphors. New York: Picador.

$\begin{array}{llllll}\text { Telangana, } & \text { T. } & \text { (2020). } & \text { Retrieved } & \text { August } & \text { 22, 2020, from }\end{array}$ https://telanganatoday.com/diseases-devastation-and-poetry

Watt, I. (2000). The Rise of the Novel: Studies in Defoe, Richardson and Fielding. London: Pimlico.

\section{Notes}

Note 1. In the Preface of Oliver Sacks' The Man Who Mistook His Wife for a Hat, Sacks, as a physician, says that "my work, my life, is all with the sick" and cites an idea from Friedrich Nietzsche, saying that "As for sickness: are we not almost tempted to ask whether we could get along without it?"

Note 2. Thomas Fuller points out that people cannot recognize the importance of being healthy until they lose their health. See "Thomas Fuller Quotes." Retrieved August 20, 2020, from https://www.azquotes.com/quote/104150

Note 3. According to Friedrich Nietzsche, the meaning of illness is defined as a clumsy attempt to arrive at health. See "Friedrich Nietzsche Quotes About Illness." Retrieved August 20, 2020, from https://www.azquotes.com/author/10823-Friedrich_Nietzsche/tag/illness

Note 4. The definition of pathology is "the study of the causes and effects of disease or injury." See "pathology" of Wikipedia. Retrieved August 22, 2020, from https://en.wikipedia.org/wiki/Pathology

Note 5. See Oliver Sacks' Preface of The Man Who Mistook His Wife for a Hat.

Note 6. See Oliver Sacks' Preface of The Man Who Mistook His Wife for a Hat.

Note 7. See Oliver Sacks' Preface of The Man Who Mistook His Wife for a Hat. 
Note 8. See Michel Foucault's “The Prose of the World" in The Order of Things on page 29. "what determines the form of knowledge (for knowledge can only follow the paths of similitude), and what guarantees its wealth of content...."

Note 9. Here, "the disease" means TB by Susan Sontag in Illness as Metaphors. See page 20.

Note 10. In The Plague, Dr. Bernard Rieux acknowledges that he is the narrator of this chronicle: "this chronicle is drawing to an end, and this seems to be the moment of Dr. Bernard Rieux to confess that he is the narrator".

Note 11. Father Paneloux quotes scripture about plague in the biblical story in Exodus. See page 99 in The Plague.

\section{Copyrights}

Copyright for this article is retained by the author, with first publication rights granted to the journal.

This is an open-access article distributed under the terms and conditions of the Creative Commons Attribution license (http://creativecommons.org/licenses/by/4.0/). 